\title{
SOME SENSORY SYNDROMES IN CHILDREN : INDIFFERENCE TO PAIN AND SENSORY NEUROPATHY
}

\author{
BY
}

\author{
T. E. OGDEN*, FRANCOISE ROBERT, and E. ARNOLD CARMICHAEL \\ From the Neurological Research Unit, Medical Research Council, the National Hospital, \\ Queen Square, London
}

It is the purpose of this paper to direct attention to several curious and infrequently encountered conditions which may present in infancy or early childhood with a similar clinical picture. Failure to react normally to painful or noxious stimuli is the outstanding feature, and this abnormality is usually first recognized when the patient is undisturbed by an injury which obviously should be painful. As most of these conditions bear a superficial resemblance to one another we suggest employing the general term "sensory syndrome" to describe them, and have been fortunate in being able to examine five examples. By reporting illustrative cases we propose to bring forward evidence indicating that several pathological conditions are included in this clinical picture.

\section{Congenital Indifference to Pain}

In the first condition, congenital indifference to pain, there is no objective neurological abnormality except that the patient, although recognizing the nature of all types of stimuli at normal thresholds, fails to evince the usual clinical manifestations associated with accepted pain-producing stimulation.

Case 1. (A.C., NH 32034).--This patient is a 14-yearold girl.

Family History.-The parents are first cousins, the patient's grandmothers being sisters. There is no known neurological disease in either family. The parents and only sibling have been examined and no abnormality detected. There is no left handedness in the family.

Medical and Developmental History.-The patient was born at full term after an uneventful pregnancy and delivery. She developed normally during her first year, walked, and said a few words by her fourteenth month. When she was aged 10 months her parents noticed that she was inclined to chew her tongue, causing large ulcers which appeared to be painless and which eventually led to the destruction of the tip of the tongue. She was unsteady on her feet until the age of 3 years and never

\footnotetext{
*Present address: Department of Neurological Surgery, University of California Medical Center, San Francisco 22, California.
}

cried although she had many falls and sustained numerous minor injuries. When she was $2 \frac{1}{2}$ years old handfuls of her hair were pulled out by a playmate; at 3 she smashed her fingers in a door; at 4 she sustained a severe laceration of the forehead. In each of these injuries she exhibited no evidence of pain, and indeed, on several occasions her injury was unsuspected until noticed by her parents. At the age of 6 years her right hip became swollen over a period of two weeks. This was associated initially with a limp, which increased till eventually she complained of being unable to move the leg. Three weeks from the onset she was admitted to hospital, where a fracture of the right femur was diagnosed. At no time during this period, even while walking, did she complain of pain. At the age of 10 years she fell while playing and noticed on getting up that her wrist "bent the wrong way". She had sustained a painless compound fracture of the left wrist, which was set without anaesthesia and without causing her any discomfort.

In the three years since her last admission to the National Hospital the patient has matured considerably and has made a better adjustment to her disability. She is now careful to avoid injury and is generally successful although she occasionally finds blisters on her fingers from burns of which she has been unaware. She cannot recall having had a headache, earache, stomach ache, colic, or having experienced pain. She experiences hunger and thirst, sweats readily, and on exposure to cold has goose flesh. Her teeth are extremely carious but cause her no discomfort. She realizes when she has a foreign body in her eye but is not distressed by it.

Examination.-She is a right-handed girl whose I.Q. on the Terman-Merrill scale is 126 . Her face is wizened, causing her to look older than her stated age. Psychiatric examination does not elicit anything suggestive of a hysterical reaction. General examination is not remarkable except for the multiplicity of scars on the tongue, elbows, hands, knees, feet, and buttocks. The right femur is slightly shorter than the left and she has a hydroarthrosis of the right knee joint (Fig. 1). Both her ankle joints are deformed by bony overgrowth. She is unable to detect the odours of asafoetida, coffee, tobacco, or lavender, nor can she taste sugar, salt, quinine, or tartaric acid. It is possible that her loss of taste may be related to the extensive scarring of the tongue. There is no wasting or other abnormality of development, power, 


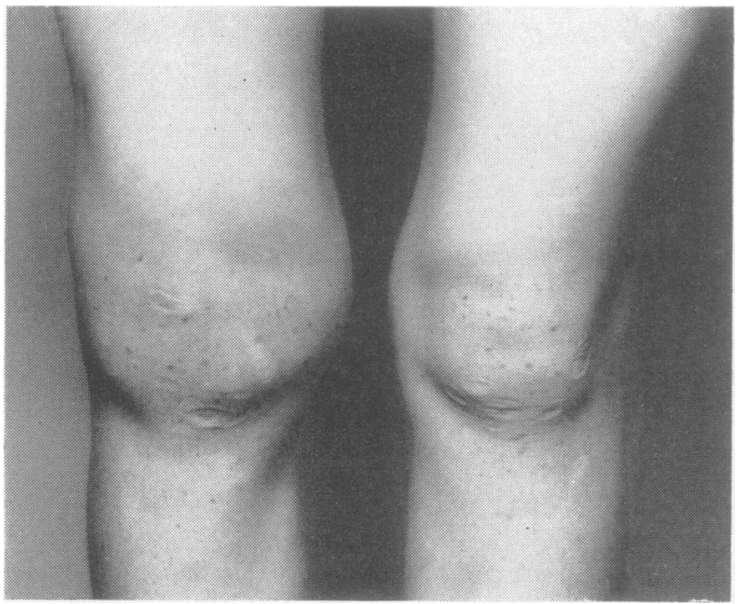

FIG. 1.-Multiple scars of both knees and bony deformity of the right knee joint.

tone, or coordination of the muscles of the extremities. Her gait is normal. The tendon reflexes are present and symmetrical, and the plantar responses are flexor. The corneal reflexes can be elicited, but are less brisk than normal. Light touch and tickling with a wisp of cotton, small ranges of movement at joints, vibration and discrimination between one and two closely placed points of contact on the finger tips are all normally perceived. She is able to detect small differences in the temperature of an object placed against her skin, and to distinguish easily between the sharp and blunt ends of a pin. Recognition of the nature of objects placed in her hands when her eyes are closed is good. Her sensory threshold has been examined, using as a stimulus a square wave electrical pulse of 1 millisecond's duration and variable strength provided by a constant voltage stimulator (Walter and Ritchie, 1945). This is normal everywhere, except distal to the knees where it is slightly elevated. This elevation may be the sequel to the trauma to which the legs have been subjected. The reactions usually associated with pain have not been produced even with the strongest of stimuli. Stimulation with up to 100 volts is intolerably painful to the examiner, but causes her no discomfort although it occasions violent muscular contraction. If a blood pressure cuff is inflated on her arm to $220 \mathrm{~mm}$. $\mathrm{Hg}$ she is atle to make a fist 130 times in two minutes without discomfort; on the other hand, in a healthy subject severe pain usually develops after $\mathbf{4 0}$ to 60 contractions. Immersing her hand in water at temperatures of $1^{\circ} \mathrm{C}$. and $65^{\circ} \mathrm{C}$. causes no pain and she does not object to deep pressure on the tendo Achillis. Intravenous injection of $0.25 \mathrm{mg}$. of histamine causes a bad taste in her mouth and throbbing in her head but no headache (Clark, Hough, and Wolff, 1936). Pressure on the eyeball causes the cardiac rate to drop from 96 to 84 per minute but no expression of pain. Scratching the neck results in no painful sensation but produces a change in pupil size. The cutaneous axone reflexes, tested by scratching the skin with a pin and by the intradermal injection of histamine, are normal. When liberally dusted with "itching powder" there is the usual erythematous reaction which is not, however, associated with an itching sensation. The patient's refusal to be exposed to radiant heat has prevented detailed testing of her sweating reaction. She has been observed during examination to be perspiring about the face, in the axillae, and on the palms of the hands and soles of the feet. No thickening of peripheral nerves has been noted on palpation.

Radiological studies at the age of 7 years showed an old healed fracture of the upper part of the shaft of the right femur with marked angulation of the neck. There were osteochondritic changes involving the right knee joint and avascular necrosis of the epiphysis of the left os calcis and right astragalus. These changes were accepted as traumatic in origin. Air encephalography revealed no defect of the cisterns or of the ventricular system. Dr. Hallpike found normal cochlear and vestibular functions. Electro-encephalography undertaken by Dr. Cobb showed no abnormality; the alpha rhythm blocked normally with eye opening and sudden noises. Dr. Dawson has kindly allowed us to report that he obtained through the intact scalp good evoked potentials from the cortical sensorimotor area on electrical stimulation of the ulnar nerve. The Wassermann reactions in the blood and cerebrospinal fluid were negative. The fluid contained no increase in cells or in protein. On two occasions a portion of an interdigital nerve with the overlying skin was excised from the foot and examined histologically

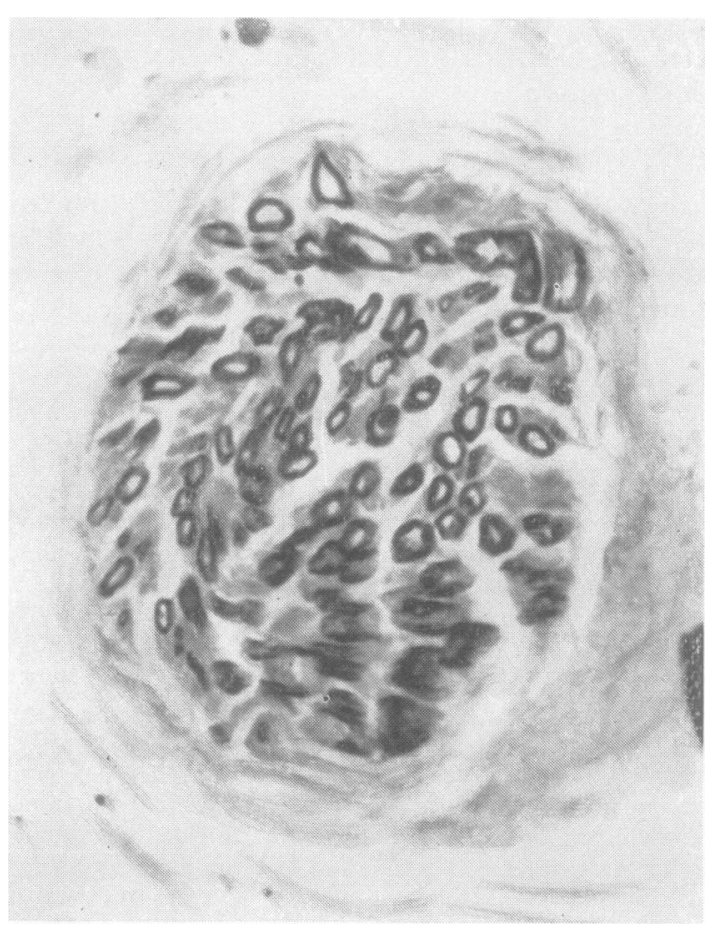

Fig. 2.-Interdigital nerve of left foot. The appearance is that of a normal nerve. (Osmic acid stain $\times 300$.) 
using a number of stains including osmic acid and methylene blue (Fig. 2). Professor Blackwood detected no abnormality of the peripheral nerves and observed many small nerve fibres in the superficial dermis. These accompanied capillaries or passed toward the basal epidermis.

To sum up, this is an intelligent girl in whom the motor system appears to be functioning normally and who reports normal responses dependent on the integrity of the peripheral autonomic nervous system. On the sensory side it has not been possible to evoke the normal reactions commonly associated with the experience of pain when a variety of stimuli have been used. The stimuli have been those accepted as producing pain, such as multiple heavy pinprick, heavy pressure on tendons, and extremes of cold and heat. Pain from structures within the head, such as may be provoked by intravenous histamine in healthy subjects, has not occurred.

Tests have shown that the peripheral and central pathways necessary for the recognition of various forms of stimulation are intact. The cardiac and pupillary responses to pressure on the eyeball and scratching the neck and the flare of the triple response of Lewis, dependent on the integrity of the peripheral sensory nerve fibres, are normal. Added information to show that the peripheral pathway is normal has been obtained by the study of suitably stained sensory nerves and skin. Further, no gross deformity of the brain has been found by air encephalography. It would therefore appear that the peripheral sensory pathway is intact, that following peripheral stimulation impulses reach those parts of the brain requisite for the recognition of the method of stimulation, but that there is an absence of the appreciation of pain. The nature of the mechanism at fault remains unknown. It is possible that it may result from some congenital anomaly of an undetermined order.

It is of interest that this patient in her early years became progressively more deformed by repeated self-inflicted injury as is usually the case with such patients (Murray, 1957; Petrie, 1953) Although her reaction deficit has remained unchanged, she has managed in recent years to avoid serious injury. This subjective improvement in her status is most probably the result of more intelligent self-management (McMurray, 1950).

The first documented description of this condition, which has been called "congenital indifference to pain", appeared under the title "A case of congenital general anaesthesia" (Dearborn, 1932). This was the now famous case of Edward H. Gibson, who achieved a degree of notoriety in vaudeville circles as "the human pincushion", allowing members of the audience to push pins into his tissues. He was a $3^{*}$ man of normal intelligence without neurological abnormality other than indifference to pain which had been present since childhood. Since 1931 over 40 cases have been referred to in the literature, most of which have been reviewed by Fanconi and Ferrazzini (1957). Critchley (1956) has quite properly pointed out that many of these cases have been inadequately studied. In some instances either the patient's intelligence has not been taken into consideration or the presence of a sensory neuropathy has not been excluded.

The significance in our case of anosmia and ageusia is difficult to assess. These defects have been reported in association with cases diagnosed as congenital indifference to pain (Roe and Leys, 1950; Madonick, 1954; Grain and von Hagen in Boyd and Nie, 1949), and will be discussed in greater detail below.

We wish to stress that the term "congenital indifference to pain" should be applied only to those patients who, perceiving correctly the nature of stimuli at normal thresholds, fail to react in the usual defensive manner with withdrawal of the offended part, acceleration of pulse and respiration, and elevation of blood pressure (Nafe and Wagoner, 1938; Wolf and Hardy, 1941) as in a healthy subject. Patients given this diagnostic label should not be mentally deficient, and should have normal deep tendon and cutaneous axone reflexes and normally innervated skin on histological examination. Further, the defective reaction to pain-producing stimuli should have been present from infancy.

\section{Progressive Sensory Radicular Neuropathy}

Denny-Brown (1951) applied the term "hereditary sensory radicular neuropathy" to a familial disease formerly called "hereditary perforating ulcer" (Hicks, 1922) or "acropathie ulceromutilante familiale" (Thévenard, 1942,1953 ). This is a familial, progressive, peripheral sensory neuropathy usually involving the feet first and more than the hands, with the sensory level rarely extending above the elbows or knees. The loss of pain appreciation is much more marked than that of the other modalities.

The following case is similar to the cases described by Denny-Brown (1951), but we have applied the term "progressive sensory radicular neuropathy". It is felt, however, that though there is no familial history this patient may be an isolated instance of the hereditary form of the disease.

Case 2 (R.B., NH 58889). - This is a 10-year-old boy.

Family History.-This boy's parents are first cousins, the paternal grandmother and maternal grandfather being siblings. There is no known neurological disease in either family. There is no left handedness in the family and the patient has no siblings. 


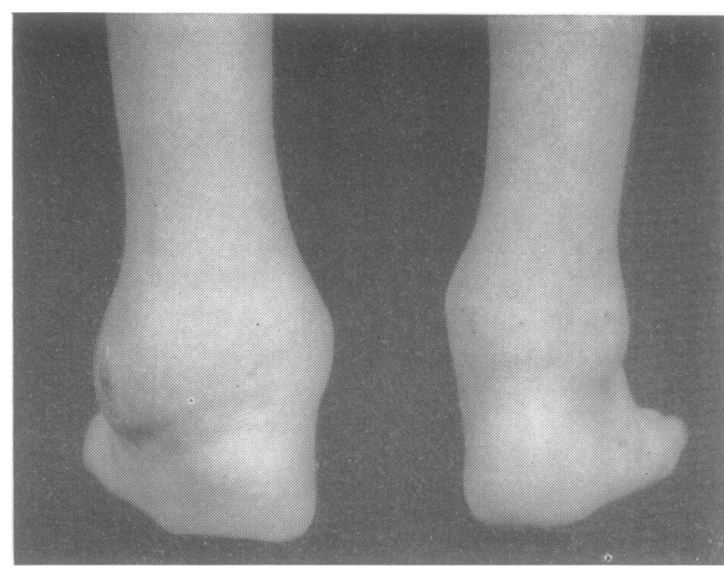

FIG. 3.-Deformity of ankles.

Medical and Developmental History.-The patient was born at full term after an uneventful pregnancy and delivery. He breathed spontaneously and appeared to be normal. He gained weight at the usual rate but did not hold up his head until the age of 6 months, sat up at 12 months, stood unassisted at 18 months, and walked at 24 months. He was continent of urine and faeces by the age of 3 years with occasional nocturnal enuresis until the age of 7 years. He was speaking words at the age of $2 \frac{1}{2}$ years and short sentences at 3 years.

When the patient was 9 months old his parents noticed that he was very clumsy in reaching for objects and did not hold things in his hands. At the age of 12 months he fell against a hot stove, sustaining a severe burn of the right hand. He neither cried nor showed any sign of distress, even though he received a third degree burn which resulted in flexion contractures of the fingers. At the age of 2 years he developed a chronic draining sinus of the left ankle, which did not heal until a fragment of bone was extruded some two years later. There has been intermittent draining since, and considerably bony deformity has developed. At the age of 4 years he became aware of his parents' interest in his unusual disability and would attract attention by placing his hand on the hot stove saying, "No hurt Bobby". When 7 years old he was admitted to the National Hospital. At that time all modalities of sensation except appreciation of temperature were severely impaired below the knees and elbows, while there was no deficit over the trunk; crude differences of temperature were recognized by him in his hands and feet. Motor power in the limbs and trunk was good. Over the years the patient has had innumerable infections of the fingers, which eventually led to the destruction of all the terminal phalanges. He has had many operative procedures without anaesthesia or discomfort. His bladder and bowel function was normal and he has experienced hunger, thirst, and headache.

Examination.-The patient is a right-handed boy with an I.Q. on the Terman-Merrill scale of 85 to 90 . The hands and left ankle are deformed (Fig. 3). The terminal phalanges of the fingers have been replaced by scar tissue or granulating wounds, and the left ankle is swollen with a small draining sinus over the lateral malleolus.

The function of the cranial nerves is normal in all respects. He is able to taste and smell. There is neither weakness nor wasting of muscles in the extremities, and coordination is good. With the exception of the triceps reflexes, which are brisk, the tendon reflexes are absent. In the limbs there is a diminution of all sensory modalities including the recognition of temperature which increases distally. The latter modality is completely absent in the left hand and both feet. The pattern of sensory loss is not perfectly symmetrical, for perception of extremes of temperature is present in the palm of the right hand, but not below the wrist of the left hand. Again, in the antecubital fossae the threshold for differentiating hot and cold is about $10^{\circ} \mathrm{C}$. on the right and nearly $15^{\circ} \mathrm{C}$. on the left. Sense of passive movement is absent at the joints of the fingers and toes. Pinprick, light touch, and vibration are not appreciated below the knees and elbows. As indicated on the sensory chart there is no impairment of sensation over the trunk (Fig. 4). An electrical stimulus of 100 volts is not felt below the wrists or knees while over the arms and thighs the threshold is about 50 volts; over the trunk it is the normal 15 to 20 volts. Pain develops after 40 contractions of the fist with a blood pressure cuff on that arm inflated to $220 \mathrm{~mm}$. $\mathrm{Hg}$. It is interesting that although the onset of the pain is within the normal "time-contraction" period the pain is not felt in the contracting muscles as is usually the case, but under the cuff. Itching and erythema may be produced by itching powder on the trunk but not on the extremities. The cutaneous axone reflexes, elicited with intradermal histamine, are readily obtainable over the trunk, are diminished over the upper part of all four limbs, and absent below the elbows and knees. Sweating occurs over the hands and feet, as elsewhere on the face and trunk. The peripheral nerves are not thickened.

FIG. 4.-The crosshatched areas indicate complete or nearly complete absence of all modalities of sensation. The vertically lined areas indicate a threshold markedly raised to pain and moderately raised to touch and temperature.

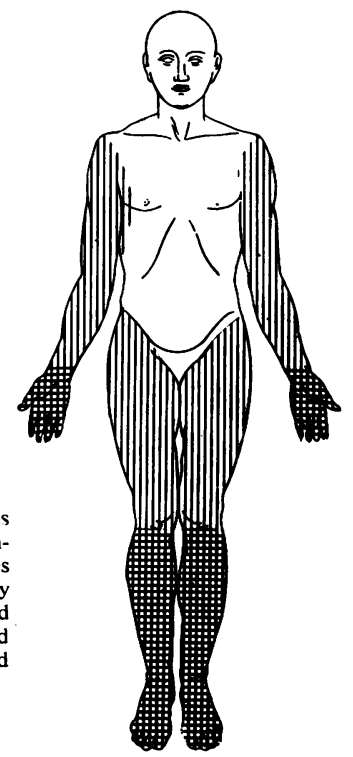




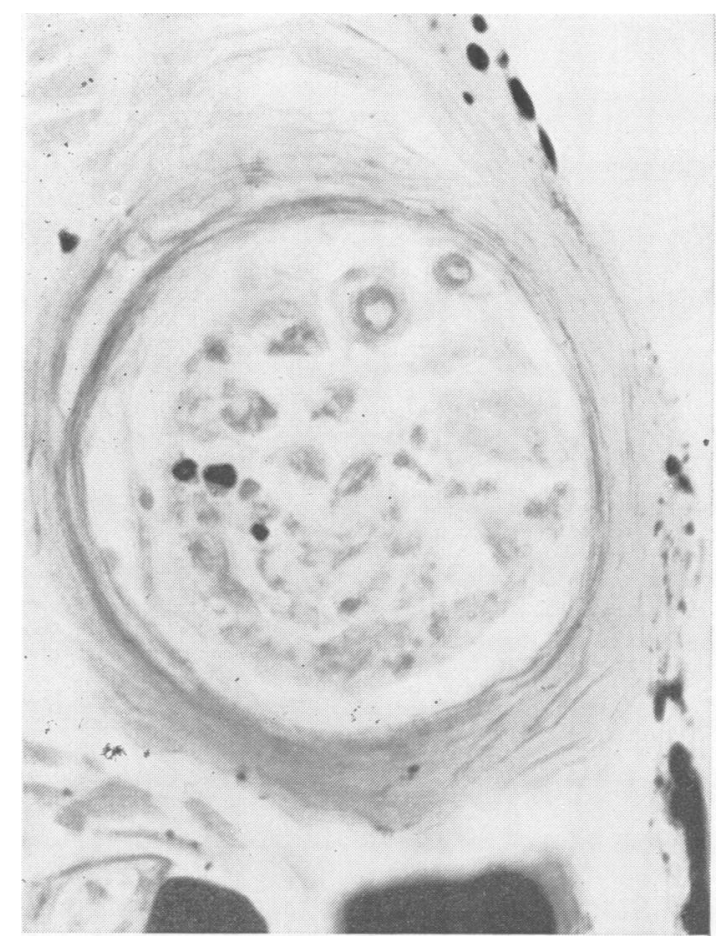

Fig. 5.-Interdigital nerve of left foot. Note the great diminution in number of myelinated fibres. (Osmic acid stain $\times 300$.)

Radiological examination (age 8 years) shows disintegration of the left ankle joint with partial absorption of the astragalus and moulding of the os calcis, partial degeneration of the interphalangeal joint, and absorption of the terminal phalanx of the right great toe, and absorption of the terminal phalanges of all the fingers. Dr. Hallpike reports normal cochlear function with severe bilateral reduction of caloric vestibular responses. Dr. Cobb reports no abnormality in the electroencephalogram. The alpha rhythm is well developed and is little affected by eye opening. Examination of the blood and cerebrospinal fluid, including the Wassermann reaction, shows no abnormality.

Histological examination of an interdigital nerve by Professor Blackwood showed several nerve bundles containing shrunken endoneural tubes. Only a few myelinated fibres could be found in the osmic acid sections (Fig.5). These findings are interpreted as being indicative of nerve degeneration.

To sum up, this is a 10-year-old boy with a progressive peripheral sensory neuropathy which probably has been present since early infancy. The sensory signs, though increasing in severity, have remained localized to the periphery of the four limbs. Associated with this sensory deficit there is a loss of axone reflexes in the analgesic areas pointing to a degeneration of the peripheral sensory neurones.
Further, the histological studies confirm the diagnosis of degeneration of the peripheral sensory neurone. On the other hand, the complete absence of any evidence of disturbance of motor function clearly indicates that the lesion involves only sensory neurones. As the peripheral autonomic motor functions are also normal, it is difficult to place the lesion anywhere except in the region of the posterior root ganglia where neither motor fibres nor autonomic fibres can be involved. This case suggests hereditary sensory radicular neuropathy because the trunk and bladder are completely spared and the disease has been slowly progressive, involving the feet more than the hands. The extremely early age of onset is unusual in the hereditary disease although several cases have been recorded (Heller and Robb, 1955). Our patient's disease is not familial, but since his parents are consanguineous it may represent the expression of a recessive trait.

\section{Non-progressive Sensory Radicular Neuropathy}

We propose to present a second case, contrasting with the previous one in that it is not progressive and the involvement is much more extensive.

This case was presented to the section of neurology of the Royal Society of Medicine on November 2, 1950, by Drs. Lorber and Carmichael. It is unfortunate that in two recent publications it has been referred to as one of congenital indifference to pain (Jewsbury, 1951; Fanconi and Ferrazzini, 1957), for it differs radically from the first case which we report in this paper.

Case 3 (R.M., NH 24347). - This is an 11 -year-old boy.

Family History.-There is no known consanguinity or history of neruological disease in either parent's family. The parents and siblings (one brother aged 12 and two sisters aged 6 and 12 when examined) were seen in 1954 and at that time showed no neurological abnormalities. One sister is left-handed.

Developmental and Medical History.-The patient was delivered at full term without instruments after an uneventful pregnancy and 24 hours' labour. He was a breech presentation and was said to have been "completely floppy" and without movement during the first few days of life. He was never cyanotic, but required tube feeding initially and had to be fed with an eyedropper until 7 months of age because of difficulty in sucking. He did not sit up without support until 18 months or stand until 4 years: he walked at $4 \frac{1}{2}$ years, but has always been unsteady with a tendency to fall, which has occasioned him many injuries. He began saying single words at 18 months. but it was not until the age of 4 years that he spoke short sentences. He was not continent of urine and faeces until the age of 6 years. At the age of 7 months he scratched his right eye causing a corneal ulceration. Surgery was necessary to preserve his sight. At this time it was first realized that he did not react normally to 
painful stimuli. At 9 months he developed a severe gastro-enteritis, which was not associated with any evidence of cramping or colic, and was followed by pneumonia. Severely ill, he was placed in an oxygen tent. His prolonged debilitation following this illness may have contributed to the retardation of his general development. As the patient grew older it became apparent that he had a marked susceptibility to infection. Many minor lacerations and burns became infected, and at one time or another he had whitlows, then osteomyelitis of each of the fingers. These infections led to the absorption of all terminal phalanges, leaving his fingers deformed and almost useless. He had many lacerations about the face, including fracture of the nasal bone, but never experienced pain with any of these injuries and infections. At the age of 9 years he was noted to be looking ill one day, although he denied feeling poorly. His temperature was $103^{\circ} \mathrm{F}$. and when he was put to bed it was noted that his left leg was swollen and red from the groin to the ankle. X-ray examination at hospital revealed an unsuspected fracture of the patella. When questioned he denied having pain in the knee and could not recall any immediate injury. When his leg was enclosed in plaster and he was confined to bed he promptly developed bed-sores over the buttocks and thigh, which did not respond to treatment until he was allowed to walk about. Throughout his life this boy has had many minor surgical procedures such as partial finger amputations and nerve biopsies without the administration of anaesthetics, yet without the slightest sign of discomfort.

At the age of 1 year the patient, in association with a fever, had a grand mal convulsion. Following this and until the age of 4 years he had about one typical petit mal seizure weekly; thereafter he has had no minor seizures and only very rare major attacks, for which he is taking "mysoline".

Examination.-This patient has been admitted to the National Hospital on six occasions in the past eight years. That there has been no change in his neurological status

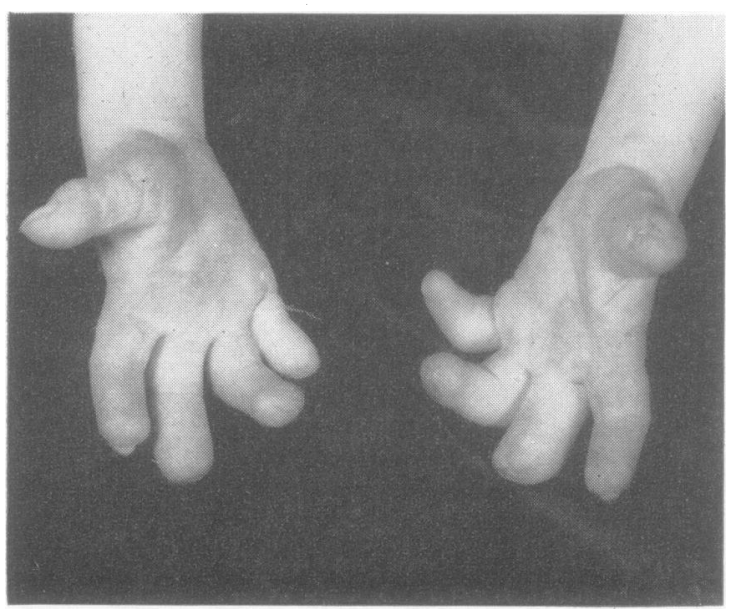

FIG. 6.-Chronically infected fingers with destruction of terminal phalanges.
FIG. 7.-Crosshatched areas indicate total loss of appreciation of all modalities of sensation. Vertically lined areas indicate additional areas of insensitivi y to pain. Sensation is normally perceived only in the left lower abdominal quadrant.

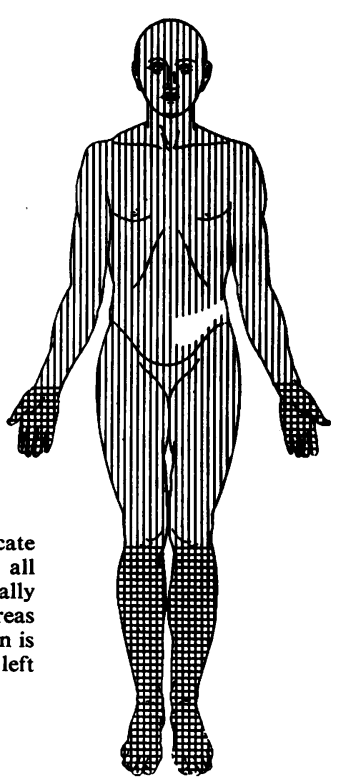

or progression of the sensory deficit during this time is well documented. His I.Q. has been repeatedly estimated at from 80 to 88 on the Wechsler children's scale (dull normal range). His countenance is rather that of a retired pugilist, for he looks much older than his years. His nose is flattened, and his mouth deformed by scars. There are innumerable scars over his hands, arms, legs, and buttocks. His fingers are stumps (Fig. 6) and there is a post-traumatic deformity of the left leg.

On examination of the cranial nerves the following abnormalities have been found: there is a complete inability to detect or differentiate the odours of lavender, cloves, and tincture of asafoetida. He raises no objection when his food is heavily adulterated with salt, sugar, or quinine, which observation suggests a total absence of taste. Visual acuity of the right eye is $6 / 12$ and of the left $6 / 9$; the reduction on the right side is due to a posttraumatic corneal opacity. There is complete loss to pain over all three divisions of the fifth nerve bilaterally with absent corneal reflexes: touch is appreciated over all three divisions, but the threshold is raised. He neither lacrimates at the smell of ammonia nor sneezes on the inhalation of snuff. Motor function of the fifth nerve is normal. There is no facial weakness. The gag reflex is absent, yet pricking of the posterior pharynx is reported by him as painful and stimulation of the trachea with a rubber catheter causes coughing. There is neither weakness nor wasting of the muscles of the trunk and upper limbs. Owing to contractures resulting from the fractured patella, extension at the left knee and hip joints is defective. Tendon reflexes are entirely lacking. The plantar responses are flexor. Only the lower abdominal skin reflexes are obtainable. Pinching and heavy pinprick are perceived as painful only over dermatomes T-10 and T-11 on the left side, and are associated with alteration in the respiratory rhythm, tachycardia, pupillary dilatation, 
protesting, and evasive movement (Fig. 7). Light touch is appreciated at normal thresholds over the thorax, where anteriorly it causes a sensation of tickle. The threshold for touch rises progressively as testing proceeds peripherally on the extremities until eventually the stimulus is not appreciated on the hands or feet. When he perceives touch he is able to localize the area stimulated with a fair degree of accuracy. Recognition of temperature differences is absent throughout except over the dermatomes T-10 and T-11 on the left where the threshold is within normal limits. Recognition of movement is absent at the joints of the fingers and toes, somewhat less impaired at the ankle and wrist and apparently normal at the elbow and knee joints. Vibration is appreciated throughout except on the fingers and toes, but the threshold is greatly raised in the hands and feet. Ability to recognize objects and two-point discrimination are absent in the hands. An electrical stimulus of 100 volts applied to the extremities or face occasions no comment from the patient, even though it causes violent muscular contractions. The threshold for recognition of such stimuli is about 70 volts in the arms and legs, and 35 volts over the thorax and abdomen with the exception of the tenth and eleventh thoracic dermatomes on the left, where a normal threshold of 15 volts is to be found. Even 100 volts are not perceived in the hands and feet. There is also an absence of the appropriate response to stimulation of a painful character such as severe compression of the tendo Achillis and testes, or following immersion of the hands or feet in water at $4^{\circ} \mathrm{C}$. There is apparently no pain in the muscle after 120 contractions of the fist in two minutes with a blood pressure cuff on the arm inflated to $220 \mathrm{~mm}$. $\mathrm{Hg}$. Dr. Hallpike reports that there is marked high tone deafness of the right ear only, and that vestibular function is normal. Examination for the state of the cutaneous axone reflexes has been carried out by the intracutaneous injection of histamine phosphate. A normal histamine flare response has only been elicited over T-10 and T-11 dermatomes on the left, but nowhere else. Itching powder applied generously causes no reaction except over the left tenth and eleventh thoracic dermatomes where itching and erythema occur.

The afferent mechanisms of deeper structures have also been investigated. Carotid body massage and carotid artery occlusion applied manually have caused no more change in pulse rate than during resting respiration. Four milligrams of sodium cyanide given intravenously with continuous spirographic control caused no change in rate or depth of respiration; hyperpnoea, which is the normal response, has not been observed (Heymans, 1955). When cystometrography is carried out the patient is aware of, but undistressed by, the catheter being passed. Strong contractions of the bladder associated with a desire to void occur with a volume of $25 \mathrm{ml}$. and again with $50 \mathrm{ml}$.: thereafter the bladder may be rapidly distended up to the level of the umbilicus $(300 \mathrm{ml}$.) without further contractions or discomfort and with only a moderate gradual rise in pressure. Again, colic-producing drugs cause no discomfort. Sweating is normal throughout, as is the psychogalvanic skin response to startle produced by striking a gong or flashing a bright light. On the other hand, cutaneous

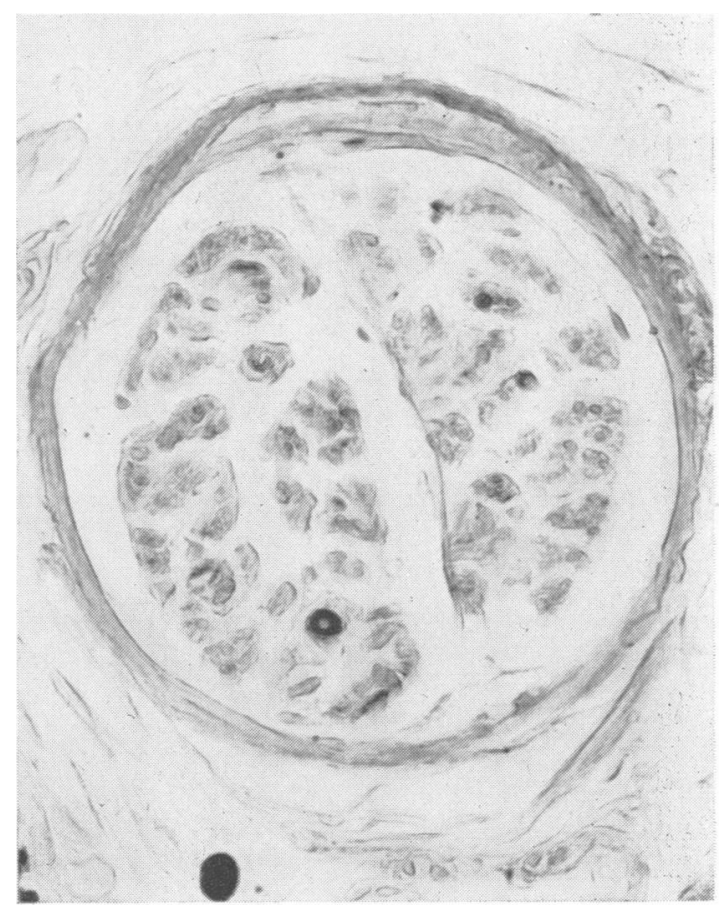

FIG. 8.--Interdigital nerve of the right foot. Note the very great diminution in number of myelinated fibres. (Osmic acid stain $\times$ 300.)

stimuli usually accepted as painful result in no autonomic response. Frequent examination by palpation of the peripheral nerves has failed to reveal any thickening.

Radiological studies show destruction of the terminal phalanges of the fingers and roughening with irregularity of the joint surfaces of the left knee. Films of the skull and spine show no bony abnormality. Air encephalography carried out at the age of 3 years showed a normalsized ventricular system. No enlargement of the cisterns or sulci was seen. Electroencepholographic studies, kindly undertaken by Dr. Cobb, have repeatedly shown background activity considered normal for his age but with scattered spiking and sharp wave activity and without evidence of focal abnormality. The alpha rhythm blocks normally with eye opening. Dr. Dawson has been unable to record through the scalp from over the sensorimotor area the presence of evoked potentials on repeated electrical stimulation of the ulnar nerve which has been of sufficient strength to cause marked contractions of the muscles supplied by that nerve (Dawson, 1956). The cerebrospinal fluid on several occasions has been normal, as have been studies of the urine and blood. Serological tests for syphilis have been negative.

Histological studies, including osmic acid stains, of interdigital nerve and skin from the dorsum of the left foot showed the nerve bundles to be filled with shrunken endoneural tubes and only one or two myelinated fibres were seen in the skin (Fig. 8). 
To sum up, this is an 11-year-old boy of fair intelligence who is unable to feel any form of stimulus applied to the distal parts of the extremities and who does not respond in the normal manner to extremely painful stimuli applied anywhere except over the left side of the abdomen where the threshold appears to be normal. The absence of reaction to pain is noted with a great variety of painful stimuli and has led to severe skin and bone trauma. The sensory defect is not accompanied by any obvious deficit in power of the muscles or by any muscular wasting. Again he sweats on the extremities and has a normal galvanic skin response to sudden noise or flashes of light. His main disability is thus one affecting the afferent mechanisms from the skin of the face, trunk, and limbs. Besides the defect of skin sensation there is a marked diminution in the response to stimulation of the carotid body, bladder, and gut. As the flare response over the limbs and trunk, apart from the small area in which painful sensations are perceived, is lacking it has been assumed that the peripheral sensory neurones have degenerated. This assumption has been confirmed by histological studies of a sensory peripheral nerve and skin. To permit somatic motor and autonomic functions the appropriate motor and autonomic nerves must be intact. A lesion which causes sensory neurone degeneration yet spares motor and autonomic fibres is most reasonably placed in the posterior root ganglion. This case differs from the hereditary form of sensory neuropathy in that it shows no family history of the disease, the onset is from birth, the involvement, including several cranial nerves, is much more widespread and it is not progressive. We believe that the presence or absence of progression is of sufficient importance to justify grouping our second and third cases respectively as "progressive" and "non-progressive" sensory neuropathy.

\section{Discussion}

We have listed in Table $I$ the distinguishing features of the several conditions under discussion which may be found in the "sensory syndrome", a condition showing defective reaction to painful stimuli. The first, congenital indifference to pain, is relatively rare but probably occurs more commonly than is generally appreciated. If such a diagnosis is to be meaningful certain diagnostic criteria have to be met in addition to that of defective reaction to painful stimuli. The most important is the absence of a demonstrable lesion involving the sensory pathways. Secondly, various forms of stimulation have to be appreciated at normal thresholds, while tendon reflexes should be normal. The only abnormality is a defective reaction to strong noxious stimuli, namely an indifference to the usual painful element. Thus the integrity of sensory paths distinguishes congenital indifference to pain from the sensory radicular neuropathies. A third important criterion is that the patient must not be mentally deficient or suffer from any obvious cerebral pathology. This is a necessary qualification in order to exclude from the group those patients with gross mental defect: it is known that mental defectives may show considerable indifference to pain (Couston, 1954). Again, since Schilder and Stengel first coined the term "pain asymbolia" (1928 a and b, 1931), a number of reports have appeared dealing with indifference to pain as a symptom of cerebral pathology (Hemphill and Stengel, 1940; Pötzl and Stengel, 1936; Rubins and Friedman, 1948); a degree of indifference may occur after prefrontal lobotomy (Freeman and Watts, 1946). Riley (1952) has described a familial condition in which have been present defective lachrymation, emotional instability, areflexia, hypertension, vomiting, and indifference to pain. As most of his patients have been mentally defective and suffered from epilepsy, it is possible

TABLE I

SIMILARITIES AND DISSIMILARITIES OF CONGENITAL INDIFFERENCE TO PAIN, CHRONIC PROGRESSIVE SENSORY NEUROPATHY, AND NON-PROGRESSIVE SENSORY NEUROPATHY COMPARED

\begin{tabular}{|c|c|c|c|c|}
\hline & & Congenital & $\begin{array}{c}\text { Progressive } \\
\text { Sensory Neuropathy } \\
\text { of Children }\end{array}$ & $\begin{array}{l}\text { Non-progr zssive } \\
\text { Sensory Neuropathy } \\
\text { of Children }\end{array}$ \\
\hline $\begin{array}{c}\text { Character- } \\
\text { istics of the } \\
\text { sensory } \\
\text { syndrome }\end{array}$ & $\begin{array}{l}\text { Defective appreciation of pain } \\
\text { Motor involvement } \\
\text { Repeated self injury } \\
\text { Disorganized joints } \\
\text { Sensory deficit (other than pain) } \\
\text { Distribution of sensory deficits } \\
\text { (all types) } \\
\text { n reflexes } \\
\text { x ve biopsy } \\
\text { transmission } \\
\text { "lesion" }\end{array}$ & $\begin{array}{lc} & + \\
& 0 \\
& + \\
& + \\
\text { Universal } & 0 \\
& \\
\text { Normal } & \\
\text { Normal } & \\
\text { Normal } & 0 \\
\text { Central to dorsal root } \\
\text { ganglion }\end{array}$ & $\begin{array}{c}+ \\
+ \\
+ \\
+ \\
\text { Greatest distally, sparing } \\
\text { thorax and cranial } \\
\text { nerves except 8th nerve } \\
\text { Absent in involved areas } \\
\text { Absent in involved areas } \\
\text { Demyelination } \\
\text { ? } \\
\text { In or distal to dorsal root } \\
\text { ganglion } \\
\text { Slow progression }\end{array}$ & 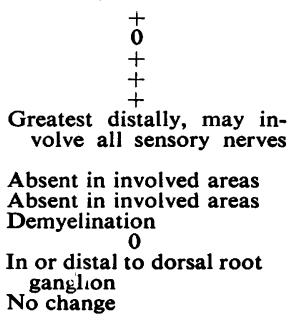 \\
\hline
\end{tabular}


that the indifference to pain has been but a manifestation of mental deficiency. Hysteria has also been mentioned as a diagnostic possibility and properly dismissed by most authors since the condition under discussion is present from early infancy, an age at which hysteria is accepted as not occurring. We feel that it is important to apply the label of "congenital indifference to pain" only to those patients with normal intelligence and with no demonstrable neurological abnormality. Using such criteria the cases published by the following authors seem to fit this group: Dearborn (1932), Kunkle and Chapman (1943), Boyd and Nie (1949), McMurray (1950) (also described by Petrie, 1953, and Feindel, 1953), Nissler and Parnitzke 1951), Kipnis, Cohen, Kubzansky, and Kunkle (1954) (also reported by Cohen, Kipnis, Kunkle, and Kubzansky, 1955), Juli_o and Brotto (1955), Jéquier and Deller (1956), Schachter (1956) and Durand and Belotti (1957). Ford and Wilkins (1938) described three cases. The first and third are typical but the second case is questionable since the patient was mentally deficient, had grand mal epilepsy and mentally defective parents. Of the four cases reported by Jewsbury (1951) three are acceptable but the fourth is unsubstantiated. Lamy, Garcin, Jammet, Aussannaire, Lambert, Thiriez, and Grasset (1956) reported two cases, the second of which (with muscle hypotonia and areflexia) should be excluded. Fanconi and Ferrazzini (1957) described three cases, the second of which was not examined and should therefore not be included in this group. We believe that the patients reported by Arbuse, Cantor, and Barenberg, (1949) having an I.Q. of 50, of Keizer (1951) being a Mongol idiot, and of Madonick (1954) with an I.Q. of 61 , should not be included in this group since marked mental deficiency was such a prominent feature. Similarly the patient described by Roe and Leys (1950), who was examined by one of us (E.A.C.) through the kind permission of the authors, was found to have an I.Q. of 50 and accordingly cannot be placed in this group. The case described by Moffie $(1951,1952)$ is complicated by organic brain damage and psychosis, making it difficult to evaluate; again, the case described by Farquhar and Sutton (1951) had tremor of the head and hands, slurred speech, unsteady gait, and a history of meningitis at the age of 1 year. (We wish to thank the authors for permission to examine this patient.) The patient described by Ortiz de Zarate (1955) clearly has histologically proven sensory neurone degeneration, absent ankle reflexes, and a psychosis, which removes the case from the group distinguished by congenital indifference to pain. The cases briefly described by Critchley $(1934,1935)$, von Hagen and Grain in discussing Boyd and Nie's paper (1949), and Ziegler and Pacella in discussing Madonick's paper (1954) may belong to this group, but without more clinical details a definitive diagnosis cannot be made with any confidence.

As to the nature or region of the dysfunction responsible for the symptoms and signs as found in congenital indifference to pain, we have no helpful observations to contribute. The literature also is remarkably lacking in observational studies.

Denny-Brown directed attention to the oscurrence of degeneration of posterior root ganglia sezondary to carcinoma of the bronchus (1948) and later as a nosologically distinct hereditary disease (1951). His work helped to terminate a controversy lasting for years concerning the underlying pathology. In the past they had been diagnosed as cases of status dysraphicus, Morvans' disease, and syringomyelia (Schultze, 1917; Guillain and Thévenard, 1929; Thévenard and Coste, 1935; Thévenard, 1942; Parks and Staples, 1945). Several exhaustive clinical and pathological studies of hereditary sensory radicular neuropathy have appeared in recent years (Thévenard, 1953; van Bogaert, 1953; Girard, Mazare, and Devic 1953; Girard, Devic, and Garin, 1953; Heller and Robb, 1955; Roger and Pujol, 1955), and as the number of reports has grown it has become apparent that many of the cases of noncarcinomatous sensory neuropathy do not fit into the clinical picture defined by Denny-Brown (1951). The patient described by Ionesco, Jonasesco, and Mester (1958) is a case in point; a young woman, normal until the age of 17 years, shortly after a severe "T.A.B. post-vaccinal reaction" necessitating admission to hospital, developed a generalized hypaesthesia with lightning pains in the legs. By the age of 20 she presented the typical "sensory syndrome" picture with perforating ulcers of the feet, loss of several toes, and a left corneal ulcer associated with disturbance of sensation over the first division of the left fifth cranial nerve. The sensory deficit has not progressed. She showed no motor involvement. No family history of neurological disease could be elicited. The findings in this patient closely resemble those of our case (R.M.), except that this came on in early adult life. She may well represent an instance of non-progressive sensory neuropathy.

The patient described separately by Munro (1956) and by Walker (1955-56) has been examined recently by one of us through the courtesy of Dr. P. Sandifer. This is a boy, now aged 13 years, whose parents are first cousins. He has been noted to be indifferent to painful stimuli since infancy and presents as a typical case of the "sensory syndrome" with rather more involvement of the lower than the upper extremities. Perforating ulcers of the left foot have 
led to a mid-tarsal amputation. That he is suffering from a neuropathy has been confirmed by biopsy of an interdigital sensory nerve. There is no motor involvement. This case is interesting for several reasons. The family history is negative for neurological disease. The patient has a moderate low tone deafness, and although he can hear a conversational tone quite clearly his verbal comprehension is extremely poor. His I.Q. on performance testing is well above average (I.Q. 110) but on verbal testing is severely defective (I.Q. 50). Careful comparison of past examinations with ours revealed no evidence of progression of the sensory deficit. We wish to suggest that this child probably has a non-progressive sensory neuropathy similar to that of our case (R.M.).

The cases reported by Parks and Staples (1945), Ortiz de Zarate (1955), and Head (1903), to name but a few, probably also represent the non-progressive rather than the progressive form of sensory neuropathy.

\section{Summary}

The "sensory syndrome", a non-specific clinical picture by which several aetiologically unrelated conditions may manifest themselves in children, is described. Its outstanding features are insensitivity or indifference to pain with failure to avoid noxious stimuli and repeated self injury. There may be a marked susceptibility to infection with perforating ulcers of the feet, osteomyelitis, and loss of terminal phalanges of fingers and toes. Disorganized joints are common.

Cases are presented to illustrate three unrelated instances of the "sensory syndrome" in children. (1) Congenital indifference to pain, a condition in which, as far as can be determined, the patient's sensory apparatus is intact, but he fails to react normally to painful stimuli. (2) Progressive sensory radicular neuropathy, a sensory neurone degeneration in the distal parts of the extremities which involves the feet more than the hands and is progressive. It is clinically indistinguishable from hereditary sensory radicular neuropathy and may represent sporadic instances of this disease. (3) Nonprogressive sensory neuropathy, a widespread sensory neurone degeneration involving cranial and thoracic nerves as well as those of the limbs. The deficit is more scattered and asymmetrical than in the progressive disease and there is no progression. The aetiology of these diseases is unknown.

\section{REFERENCES}

Arbuse, D. I., Cantor, M. B., and Barenberg, P. A. (1949). J. Pediat., 35, 221. . (1953). Acta neurol. belg.. 53. 37.

Bogaert, van L. (1953). Acta neurol. belg.. 53. 37.
Boyd, D. A., and Nie L. W. (1949). Arch. Neurol. Psychiat. (Chicago), 61,402 .

Clark, D., Hough, H., and Wolff, H. G. (1936). Arch. Neurol. Psychiat. (Chicago), 35, 1054.

Cohen, L. D., Kipnis, D., Kunkle, E. C., and Kubzansky, P. E. (1955). J. abnorm. soc. Psychol., 51, 333.

Couston, T. A. (1954). Brit. med. J., 1, 1128.

Critchley, M. (1934). Ibid., 2, 891 .

Crich). Bristol med.-chir. J., 52, 191.

(1956). Ann. intern. Med., 45, 737.

Dawson, G. D. (1956). J. Physiol. (Lond.), 131, 436.

Dearborn, G. (1932). J. nerv. ment. Dis., 75, 612

Denny-Brown, D. (1948). J. Neurol. Neurosurg. Psychiat., 11, 73.

(1951). Ibid., 14, 237.

Durand, P., and Belotti, B. M. (1957). Helv. paediat. Acta, 12, 116.

Fanconi, $\mathbf{G}_{.,}$and Ferrazzini, $\mathrm{F}_{\text {. (1957). Ibid., 12, } 79 .}$

Farquhar, H. G., and Sutton, T. (1951). Lancet, 1, 827.

Feindel, W. (1953). J. Bone Jt Surg., 35B, 402.

Ford, F. R. and Wilkins, L. (1938). Bull. Johns Hopk. Hosp., 62, 448

Freeman, W., and Watts, J. W. (1946). Lancet, 1, 953.

Girard, P. F., Devic, M., and Garin, A. (1953). Rev. neurol., 88, 198.

, Mazare, Y., and Devic, M. (1953). Acta neurol. belg., 53, 82

Guillain, G., and Thévenard, A. (1929). Ann. Med., 25, 267.

Head, H. (1903). Lond. Hosp. Gaz., Clinical Supplement. 10, 5.

Heller, I. H., and Robb, P. (1955). Neurology (Minneap.), 5,15 .

Hemphill, R. E., and Stengel, E. (1940). J. Neurol. Psychiat., 3, $25 \mathrm{i}$.

Heymans, C. (1955). Pharmacol. Rev., 7, 119.

Hicks, E. P. (1922). Lancet, 1, 319 .

Ionesco, I., Ionasesco, V., and Mester, Z. (1958). Acta neurol. belg., $58,260$.

Jéquier, M., and Deller, M. (1956). Confin. neurol. (Basel), 16, 207. Jewsbury, E. C. O. (1951). Brain, 74, 336.

Julião, O. F., and Brotto, W. (1955). Arch. Neuro-psiquiat. (S. Poulo), $13,338$.

Keizer, D. P. R. (1951). Lancet, 1, 1020.

Kipnis, D. M., Cohen, L. D., Kubzansky, P. E., and Kunkle, E. C. (1954).' Trans. Amer. neurol. Ass., 79, 105.

Kunkle, E. C., and Chapman, W. P. (1943). Ass. Res. nerv. Dis. Proc. 23, 100 .

Lamy, M., Garcin, R., Jammet, M. L., Aussannaire, M., Lambert, A., Thiriez, H., and Grasset, A. (1956). Sem. Hôp. Paris, 32, 2823.

McMurray, G. A. (1950). Arch. Neurol. Psychiat. (Chicago), 64,

Madonick, M. J. (1954). Neurology (Minneap.), 4, 554.

Moffie, D. (1951). Confin. neurol. (Basel), 11, 219.

- (1952). Ned. T. Geneesk., 96, 1177.

Munro, Margaret (1956). Brit. med. J., 1, 541.

Murray, R. O. (1957). Brit. J. Radiol., 30, 2.

Nafe, J. P., and Wagoner, K. S. (1938). Amer. J. Psychol., 51, 118.

Nissler, K., and Parnitzke, K. H. (1951). Dtsch. med. Wschr., 76,

Ortiz de Zarate, J. C. (1955). Encéphale, 44, 414.

Parks, H., and Staples, O. S. (1945). Arch. intern. Med., 75, 75.

Petrie, J. G. (1953). J. Bone Jt Surg., 35B, 399.

Pötzl, O., and Stengel, E. (1936). Jb. Psychiat. Neurol., 53, 174.

Riley, C.'M. (1952). J. Amer. med. Ass., 149, 1532.

Roe, W., and Leys, D. G. (1950). Proc. roy. soc. méd., 43, 250.

Roger, J., and Pujol, R. (1955). Marseille-méd., 92, 159.

Rubins, J. L., and Friedman, E. D. (1948). Arch. Neurol. Psychiat. (Chicago), 60, 554.

Schachter, M. (1956). Praxis, 45, 681.

Schilder, P., and Stengel, E. (1928a). Z. ges. Neurol. Psychiat., 113, 143.

143. (1928b). Klin. Wschr., 7, 535.

(1931), Arch. Neurol. Psychiat. (Chicago), 25, 598.

Schultze, F. (1917). Disch. med. Wschr., 43, 545.

Thévenard, A. (1942). Rev. neurol., 74, 193.

- (1953). Acta. neurol. belg., 53, 1.

- and Coste, M. (1935). Rev. neurol., 63, 195

Walker, C. H. M. (1955-56). Gt Ormond Str. J., No. 10, p. 72

Walter, W. G., and Ritchie, A. E. (1945). Electronic Engng, 17, 585.

Wolf, S., and Hardy, J. D. (1941). J. clin. Invest., 20, 521. 